\title{
A dynamic distention protocol for whole-organ bladder decellularization: histological and biomechanical characterization of the acellular matrix
}

Consolo $\mathrm{F}^{1^{*}}$, Brizzola $\mathrm{S}^{2}$, Tremolada $\mathrm{G}^{2}$, Grieco $\mathrm{V}^{3}$, Riva $\mathrm{F}^{3}$, Acocella $\mathrm{F}^{2}$, Fiore $\mathrm{GB}^{1}$ and Soncini $\mathrm{M}^{1}$

${ }^{1}$ Department of Bioengineering, Politecnico di Milano, P.zza Leonardo da Vinci 32, 20133, Milano, Italy

${ }^{2}$ Department of Health, Animal Science and Food Safety, Surgery Unit, Faculty of Veterinary Medicine, Università delgi Studi di Milano, via Celoria, 10 - 20133 Milano, Italy

${ }^{3}$ Department of Veterinary Science and Public Health, Faculty of Veterinary Medicine, Università degli Studi di Milano, via Celoria, 10 - 20133 Milano, Italy

\section{"Corresponding author:}

Filippo Consolo, $\mathrm{PhD}$

Department of Bioengineering, Politecnico di Milano

P.zza Leonardo da Vinci 32, 20133, Milano, Italy

Phone: +39.0223994144

Fax: +39.0223993360

This is the peer reviewed version of the following article: Consolo, F., Brizzola, S., Tremolada, G., Grieco, V., Riva, F., Acocella, F., Fiore, G. B. and Soncini, M. (2013), A dynamic distention protocol for whole-organ bladder decellularization: histological and biomechanical characterization of the acellular matrix. J Tissue Eng Regen Med. doi: 10.1002/term.1767, which has been published in final form at Wiley web site (http://onlinelibrary.wiley.com/doi/10.1002/term.1767/full). This article may be used for non-commercial purposes in accordance with Wiley Terms and Conditions for Self-Archiving (http://olabout.wiley.com/WileyCDA/Section/id820227.html - terms). 


\begin{abstract}
A combined physical-chemical protocol for whole full-thickness bladder decellularization is proposed, based on organ cyclic distention through repeated infusion/withdrawal of the decellularization agents through the urethra. The dynamic decellularization was intended to enhance the cell removal efficiency facilitating the delivery of the detergents within the inner layers of the tissue and the removal of cell debris. The use of mild chemical detergents (hypotonic solution and non-ionic detergent) was employed to limit adverse effects upon matrix 3D ultrastructure. Inspection of the presence of residual DNA and RNA was carried out on decellularised matrices to verify effective cell removal. Histological investigation was focused on assessing the retention of adequate structural and functional components that regulate the biomechanical behavior of the acellular tissue. Biomechanical properties were evaluated through uniaxial tensile loading tests of tissue strips, and through ex vivo filling cystometry to evaluate the whole organ mechanical response to a physiological-like loading state. According to our results, a dynamic decellularization protocol of $17-\mathrm{h}$ duration with a $5-\mathrm{ml} / \mathrm{min}$ detergent infusion flow rate revealed higher DNA removal efficiency with respect to standard static decellularization, resulting in residual DNA content $<50 \mathrm{ng} / \mathrm{mg}$ dry tissue weight. Furthermore, the collagen network and elastic fibers distribution were preserved in the acellular ECM, which exhibited suitable biomechanical properties in the perspective of its future use as an implant for bladder augmentation.
\end{abstract}

Keywords: bladder acellular matrix, whole-organ decellularization, bladder tissue engineering, biologic scaffold.

Running Title - whole bladder dynamic decellularization 


\section{Introduction}

In the last decade, biologic scaffolds derived from decellularized tissues have been successfully used in preclinical animal studies and in human clinical regenerative medicine applications, with promising results reported in the regeneration of several tissues/organs Atala (2007), Badylak et al. (2009). The clinical success of acellular tissues is due to the unique biochemical and biomechanical properties of these matrices Kim et al. (2008), Brown et al. (2010). The ultimate goal of decellularization is to remove from the tissue all the cellular and nucleic material responsible of adverse inflammatory or immune response, elicited by cell membrane epitopes and nucleic DNA, while retaining the complex mixture of structural and functional proteins that constitute the native extracellular matrix (ECM) Gilbert et al. (2006). Ideally, decellularization has the potential to produce a functional implant with preserved in vivo-like composition and physical properties, together with bioactive factors favorably acting as modulators of cell behaviour, eliciting cellular biologic recognition and specific cell-matrix interactions, encouraging cell proliferation and infiltration, and enhancing tissue regeneration and remodeling Kim et al. (2008). Because components of the ECM are generally conserved across different species, allogeneic/xenogeneic decellularized matrices can be implanted without inducing any adverse host response Brown et al. (2006). Furthermore, the implant of a biological-derived tissue patch with native biomechanical properties enhances in vivo engraftment with host tissues, leading to a proper functional recovery.

In this context, bladder acellular matrix (BAM) is increasingly used for the regeneration of the urinary bladder Obara et al. (2006), Urakami et al. (2007), Loai et al. (2010), Davis et al. (2010). According to current literature, great efforts have been made to establish a decellularization protocol for the production of a functional BAM. Recent studies reported the ingrowth of urothelial, smooth muscle and endothelial cells, and of nerve tissue into the implanted acellular patch from adjacent bladder parenchyma, with partly improved bladder functionality after BAM grafting as a bladder augmentation Reddy et al. (2000), Brown et al. (2002). However, several drawbacks severely affecting the long-term bladder functionality still remain to be overcome before to consolidate the BAM implant procedures as a routinely clinical practice. Yang et al. recently suggested that unsatisfactory results might be attributed to the disruption of ECM constituents induced by the decellularization process Yang et al. (2010). Most of the current decellularization protocols, commonly combining a variety of physical (pressure gradient, snap freezing, electroporation, agitation, sonication, etc.), chemical (tissue detergents exposure), and enzymatic (nuclease digestion, trypsin exposure, etc.) approaches Gilbert et al. (2006), are based on tissue static incubation within decellularising agents containing solutions. In those experiments, the bladder was exposed for long time (varying between 
$48 \mathrm{~h}$ and $72 \mathrm{~h}$ ) to the action of the detergents to achieve complete cell elimination, neglecting the effects upon the ECM components and the mechanical properties of the decellularized tissues Yang et al. (2010). Crapo et al. reported that prolonged exposure of the tissues to the action of chaotropic (e.g., EDTA) and enzymatic (e.g., trypsin) agents to completely remove cellular material, could denaturize structural and functional ECM proteins, therefore inhibiting the postulated beneficial properties of the cell-free ECM Crapo et al. (2011). Furthermore, despite characterized by high cell removal efficiency, ionic detergents (e.g., sodium dodecyl sulfate, SDS) have been reported to cause irreversible tissue swelling, protein denaturation and a drop in biomechanical properties with respect to native tissue. They have also been indicated as a possible source of cytotoxicity events responsible for poor cell re-population in in vitro experiments Gratzer et al. (2006), Liao et al. (2008), Yang et al. (2009). Nucleases, in addition, may be difficult to remove from the tissue and are suspected to possibly invoke an immune response Rieder et al. (2004), Crapo et al. (2011).

Recently, a number of groups have investigated new-conception strategies for dynamic whole organ decellularization, consisting on continuous or cyclic perfusion of the decellularising agents throughout the vascular network Ott et al. (2008), Shupe et al. (2010), Petersen et al. (2010), Baptista et al. (2011), Song and Ott (2011). This approach presents three main advantages with respect to static protocols. Firstly, decellularization efficiency increases: perfusion minimizes the diffusion distance for detergents to cells in the inner layers of the tissue, facilitating the delivery of the chemical agents within the deeper parenchyma and the elimination of cellular debris. Secondly, dynamic perfusion allows shortening the overall treatment duration, therefore limiting the adverse effect of the decellularising agents upon ECM proteins. Thirdly, a whole-organ decellularization yields to the attainment of an acellular scaffold preserving the threedimensional (3D) architecture of the organ, together with the biochemical and biomechanical properties of the native ECM Crapo et al. (2011), Badylak et al. (2011). In this perspective, the whole organ dynamic decellularization approach is particularly valuable for bladder decellularization. Indeed, the ability of the bladder to allow organ expansion to fill and store relatively large volumes of urine under little increase in intravescical pressure is the result of a complex property mediated by the interaction among the smooth muscle cells, their 3D spatial arrangement within the ECM wall, and, considerably, the passive elastic properties of the bladder connective tissue Andersson and Arner (2004), Korossis et al. (2009).

In this study, we present a new dynamic decellularization protocol combining a physical and a chemical approach to obtain a BAM from whole-organ intact full-thickness rabbit bladder. In the proposed approach, whole-bladder dynamic mechanical distention was applied to exploit the possibility to enhance cellular and nucleic material removal efficiency with respect to standard static incubation approaches. In particular, we 
adapted the protocol described in Baptista et al. Baptista et al. (2011) for whole liver decellularization, consisting in organ perfusion with mild chemical detergents. In the present work, we performed cyclic mechanical distention of the whole-bladder involving the use of the same mild chemical detergents suggested by Baptista and colleagues Baptista et al. (2011), thus being more conservative in terms of tissue integrity and ECM ultrastructure preservation with respect to state of the art bladder decellularization protocols. Dynamic decellularization was carried out by a multi-channel system designed for enabling the bladder to be cyclically distended throughout the whole process by detergent infusion via the urethra. Infusion/draining cycles were aimed at: i) allowing bladder wall distention to entirely exposing the wall surface to the action of the chemical agents, ii) allowing the detergents to better penetrate within the inner layers of the bladder wall, thanks to a mild pressure gradient-induced effect, iii) facilitating the cell debris removal through continuous tissue washing. To validate the established protocol, after verification of adequate DNA and RNA removal in the acellular tissue, histological observations were combined with a comprehensive biomechanical characterization of the acellular bladders, to evaluate the effectiveness of the protocol in preserving composition, 3D architecture and biomechanical behaviour of the BAM and to evaluate whether in vivo-like whole-organ specific distention properties were preserved in the acellular organ.

\section{Materials and Methods}

\subsection{Specimen procurement}

Whole bladders from 6-months-old male rabbits were obtained from a local abattoir. Bladders were harvested immediately after animal slaughtering and transported to the laboratory within Eurocollins solution (Eurocollins solution kit, Monico S.p.A., Italy) to preserve organ viability. To perform decellularization of the whole organ within the dynamic distention system, the urethra was cannulated (Surflo* Teflon I.V. catheter $14 \mathrm{G} \times 2^{1 / 2}$, , Terumo Medical Corporation, USA), and the ureters ligated with silk sutures (3-0 USP Perma



\subsection{The decellularization protocol}

Bladders were connected through the catheterized urethra to the multi-channel dynamic decellularization system (Fig. 1, see appendix for details) enabling i) bladder distention, by intravescical infusion of detergents, and ii) bladder voiding, through detergent draining, cyclically and alternately repeated for predeterminable time duration to replicate the bladder natural cyclic filling/voiding dynamics. $A$ three-phase protocol was employed, involving the use of 1 ) hypotonic solution (de-ionized water) to cause cell lysis by 
osmotic shock (phase 1, duration $\mathrm{T}_{1}$ ), 2) non-ionic detergent (1\% Triton $\mathrm{X}-100$ with $0.1 \% \mathrm{NH}_{4} \mathrm{OH}, \mathrm{Sigma-}$ Aldrich, Co, St. Louis, MO, USA) to remove cellular and nucleic materials (phase 2, duration $\mathrm{T}_{2}$ ), and 3) deionized water recirculation to wash out cell debris and the residual decellularization detergents (phase 3 , duration $\mathrm{T}_{3}$ ). During each phase, the related fluid was used both for bladder immersion and for intraluminal infusion. Bladder filling was performed at a constant flow rate and the bladders distended up to a maximum pre-set intravescical volume preventing wall overstretching. The maximum distention volume was determined experimentally through analysis of the pressure-volume (P-V) relationship (for details, see section 2.5). Different dynamic protocols were tested varying selectively the phase duration sequence $\left(T_{1}+T_{2}+T_{3}\right)$ and the infusion flow rate, to find a suitable tradeoff between the needs for an efficient cell removal and limiting the ECM exposure time to the chemical agents. A static decellularization campaign was conducted as a control: in the static campaign, bladders were sequentially incubated in the same detergents used in the dynamic protocol with equivalent distention volume and phase duration. Thanks to combined intravescical organ filling and organ incubation in decellularising agents containing solution, both in the static and dynamic decellularization protocols the abluminal and adluminal surfaces of the bladders were exposed to the action of the decellularising agents. All the procedures were carried out at room temperature. In table 1 , the details of the dynamic and static decellularization protocols are summarized.

\subsection{Histological examination}

Histological analysis was used as a first line of inspection to assess the efficiency of the decellularization process. Fresh and decellularized tissue samples extracted from the lower body region of the organ were fixed in $10 \%(v / v)$ neutral buffered formalin, dehydrated through graded alcohols, clarified in xylene and embedded in paraffin. Haematoxylin and Eosin (H\&E) staining was used to evaluate whether nucleic structures could be observed within the decellularised tissue. The Mallory's trichrome stain (Special Stain Kit Mallory trichrome, DiaPath, Martinengo, Italy) and the Orcein stain (NovaUltra Orcein Elastin Stain Kit, IHCWorld, LLC, Woodstock, USA) were used to evaluate the degree of preservation of collagen and elastic fibers within the acellular ECM. A score was assigned $(0=$ not preserved; $1=$ poorly preserved; 2 = moderately preserved; $3=$ well preserved) to denote the degree of maintenance of the specific distribution pattern of collagen and elastic fibers (Grauss et al., 2005).

\subsection{Extraction and quantification of DNA and RNA}


Quantitative evaluation of residual DNA and RNA was performed on the decellularised tissues and compared with native bladder. DNA and RNA extraction was performed from samples from the lower-body region of the organ, as previously described Turin et al. (2000), Riva et al. (2010). The concentration of DNA and RNA was determined using a spectrophotometer (BioPhotometer, Eppendorf, Hamburg, Germany) at $260 \mathrm{~nm}$ wavelengths. The values of DNA and RNA contents were expressed as the ratio between the weight of DNA and RNA per tissue dry weight $(\mu \mathrm{g} / \mathrm{mg})$.

\subsection{Biomechanical characterization}

Uniaxial tensile loading (UTL) tests were carried out on samples retrieved from the lower-body (LB) region of the bladder to characterize the biomechanical properties of full-thickness native rabbit bladders. Moreover, we compared the biomechanical behavior of the dynamic vs the static group to selectively discriminate between potential differences attributable to the decellularising chemical environment alone or to its use in combination with a repeated mechanical distention. The directional anisotropy of the bladder wall was also investigated by retrieving and testing specimens along the apex-to-base (LB-AB) and transversal (LB-T) directions. UTL tests were performed using a servo-hydraulic material-testing machine (MTS Uniaxial Testing Machine, MTS System Corporation, MN, USA). The decellularized bladders were tested within $24 \mathrm{~h}$ from the end of the decellularization process. Before the tests, the specimens were conserved in Eurocollins solution at $4^{\circ} \mathrm{C}$. Dog-bone shaped tissue strips of $4-\mathrm{mm}$ width and $20-\mathrm{mm}$ length were dissected with a block cutter. A sandpaper frame was constructed around the specimens as described in Dahms et al. Dahms et al. (1998) to facilitate uniform gripping and to avoid sample slippage from the machine clamps during tensile tests. The thickness of each strip was measured with a micrometer $(0.05 \mathrm{~mm}$ scale) in three different regions along the specimen length and the mean value used for mechanical parameters calculation. Stress-strain curves were derived from the load-displacement curves obtained from UTL tests and six parameters were calculated according to Korossis et al., Korossis et al. (2009) which characterize the typical quasistatic stress-strain behaviorof the bladder wall (Fig. 2): i) ultimate tensile stress $\left(\sigma_{\max }\right)$, ii) ultimate tensile strain $\left(\varepsilon_{\max }\right)$, iii) transition stress $\left(\sigma_{\text {trans }}\right)$, iv) transition strain $\left.\left(\varepsilon_{\text {trans }}\right), v\right)$ low-strain elastic modulus $\left(E_{\text {low }}\right)$, and vi) highstrain elastic modulus $\left(E_{\text {high }}\right)$.

\subsection{Whole-organ analysis of the bladder wall distention properties}

An experimental set-up was developed for the ex-vivo filling cystometry curve measurement of whole bladders (Fig. 3A), to describe the intravescical pressure behavior associated to continuous bladder filling. 
Native bladders were tested approximately $4 \mathrm{~h}$ after the organ explant; for decellularized samples, the cystometric analysis began immediately after the end of the decellularization. The bladders were catheterized via the urethra with a 9Fr bilumen catheter (UDCDL090, BEL Bioengineering Laboratories, IT), immersed in an organ bath containing saline solution and, via a 3-way stopcock, connected to a peristaltic pump (323D, Watson-Marlow, USA) and to a pressure sensor (26PC flow-through, Honeywell, USA). Bladders were infused with saline solution at a $1 \mathrm{ml} / \mathrm{min}$ flow rate and the intravescical pressure continuously measured and acquired via a I/O hardware and a custom-made software interface (DAQcard-6036E and LabView $^{\mathrm{TM}}$, National Instruments, USA).

\subsection{Statistical analysis}

The results of residual DNA and RNA content analysis for the three analyzed groups (native, static and dynamic) are presented as mean \pm SD. The Student-Newman-Keuls post-hoc test was performed for comparisons between individual groups after one-way ANOVA test.

The results from UTL tests are graphically represented with inter-quartile range box plots and whiskers indicating $10^{\text {th }}$ and $90^{\text {th }}$ percentile. Solid lines in box plots indicate median values of each data set. Where appropriate, the parametric Student's $t$-test/the non-parametric Mann-Whitney rank sum test were used to detect differences between two unpaired specimens in regional anisotropy test (LB-AB vs LB-T), and the parametric one-way ANOVA test/the non-parametric Kruskall-Wallis one-way ANOVA on ranks were used for comparison among specimens from the native, dynamic and static groups. In all the tests, a $p$-value $<0.05$ was accepted as statistically significant.

\section{Results}

\subsection{Histological evaluation of the decellularization efficiency}

H\&E histological staining of native and decellularised rabbit bladders are shown in figure 4. In native bladder, the presence of intact urothelium, smooth muscle bundles and cell nuclei are evidenced (Fig. 4A). Concerning dynamically decellularized samples, histological examination revealed a gradual improvement of cell removal efficiency at increasing treatment time (i.e., from the $4+4+1$ to the $8+8+1$ protocol, Fig. $4 B-D$ ). Notably, the $8+8+1$ protocol apparently yielded a complete cell nuclei removal from the tissue when associated to a $5 \mathrm{ml} / \mathrm{min}$ infusion flow rate (Fig. 4D), while visible nuclei were still present when a lower $3 \mathrm{ml} / \mathrm{min}$ flow rate was used (Fig. $4 \mathrm{E}$ ). Static decellularization was not as efficient: indeed, the $8+8+1$ static protocol did not ensure complete nuclei removal either from the urothelium or from the inner ECM layers 
(Fig. 4F). On the basis of this analysis, the bladders treated with the dynamic $8+8+1-5 \mathrm{ml} / \mathrm{min}$ protocol were considered for further characterization and compared with native tissue and the $8+8+1$ static samples.

Histological analysis with Mallory's trichrome staining (Fig. 5) revealed a partial degradation of the urothelium occurring in both the $8+8+1$ dynamic $(5 \mathrm{ml} / \mathrm{min})$ and static groups with respect to the native tissue (Fig. $5 \mathrm{~A}$ C). In turn, analysis of the collagen distribution within the acellular tissue in the dynamic group revealed a good degree of preservation of the collagen architecture (Fig. 5B, scored as 3 in Table 2), even if a partial loss of the texture of the $3 \mathrm{D}$ fibrillar structures associated to an increased interfibrillar space was noticed with respect to the native tissue (Fig. 5A). On the contrary, the collagen distribution was severely compromised in the static samples where the fibrillar architecture was almost totally lost (Fig. $5 \mathrm{C}$, scored as 1 in Table 2). In addition, while intact elastic fibers were detectable in the samples from the dynamic group (Fig. 5E, scored as 2 in Table 2), they appeared fragmented in the static group (Fig. 5F) with respect to native tissue (Fig. 5D, scored as 1 in Table 2).

\subsection{Analysis of DNA and RNA content}

The results from the analysis of residual DNA and RNA content in the tissue samples decellularised with the $8+8+1$ protocol confirm evidences from histological analysis (Fig. 6). In detail, the DNA and RNA content of native bladders $(2.635 \pm 0.186 \mu \mathrm{g} / \mathrm{mg}$ and $1.262 \pm 0.070 \mu \mathrm{g} / \mathrm{mg}$, respectively) were significantly reduced $(p<0.001)$ after both static incubation $(0.229 \pm 0.105 \mu \mathrm{g} / \mathrm{mg}$ and $0.047 \pm 0.040 \mu \mathrm{g} / \mathrm{mg})$ and dynamic decellularization with $5 \mathrm{ml} / \mathrm{min}$ infusion flow rate $(0.039 \pm 0.021 \mu \mathrm{g} / \mathrm{mg}$ and $0.065 \pm 0.023 \mu \mathrm{g} / \mathrm{mg})$. Remarkably, the dynamic distention protocol resulted in a significant reduction of residual DNA content with respect to static incubation $(p<0.05)$.

\subsection{Biomechanical characterization}

Results from UTL tests (Fig. 7) revealed no significant differences between the biomechanical behaviour of the native and treated bladder wall tissue samples ( $p>0.05$ for all the investigated parameters). Moreover, no significant differences were observable comparing the dynamic vs the static group $(p>0.05$ for all the investigated parameters). Thus, according to our results, it appears that the proposed combined physicalchemical decellularization approach is effective to yield a BAM preventing any major fail in the tissue biomechanical properties. In addition, no significant directional anisotropy (LB-AB vs LB-T samples) was observed in the uniaxial mechanical properties of the native rabbit bladder as well as after the decellularization ( $p>0.05$ for all the investigated parameters). 


\subsection{Whole-organ analysis of the bladder wall distention properties}

The maximum distention volume not overstretching the native rabbit bladder wall was determined experimentally on the basis of the evaluation of the intravescical pressure increment related to continuous organ filling. A representative cystometric curve acquired on native rabbit bladder is depicted in figure 3B showing that after an initial rapid intravescical pressure rise with the first addition of volume, the bladder responds to continuous organ filling with a little change in pressure associated to a rather large increase in volume, up to an approximately $20-\mathrm{ml}$ filling volume; after that, a further additional slight infusion of volume causes a considerable and rapid pressure increase related to a non-physiologic condition of bladder wall overstretching potentially damaging/breaking the ECM structural components. Consequently, in the decellularization campaigns, the bladders were distended up to a $20-\mathrm{ml}$ intravescical volume.

The results from cystometric analysis for native and dynamically decellularised bladders are depicted in figure 8, with P-V curves acquired on acellular organs not reproducing the trend observed in native bladders. For acellular organs, in fact, the curves were characterized by: i) an initial extensive region, extending up to a $36 \pm 4 \mathrm{ml}$ intravescical volume $\left(\mathrm{V}_{1}\right)$, in which a slow pressure increment is associated to intravescical filling, ii) a transition region with a marked increase of the pressure curve slope leading to a rapid pressure rise, followed by iii) a final region, over a $42 \pm 4 \mathrm{ml}$ intravescical volume $\left(V_{2}\right)$, in which a decreasing slope of the P$\mathrm{V}$ curve was observed. Volume $\mathrm{V}_{2}$ was assumed to be the break-point leading to bladder overstretching for the acellular samples. It is worth to notice that above the overstretching volume the acellular bladders did not respond with a sudden pressure rise, as the native bladders did (Fig. 3B), rather exhibited quasi-plateau behaviour. This occurrence may be representative of filtration of the infused fluid, due to increased permeability of the bladder wall, as a consequence of the massive cell removal, and in particular of the urothelial cells. Despite those alterations in the $P-V$ curve, notably within the $V_{1}-V_{2}$ range the acellular organs demonstrated the ability to withstand an effective pressure increment in response to intravescical filling with maximum pressure values comparable with the ones of native bladders $(2.79 \pm 0.51 \mathrm{mmHg}$ and $2.70 \pm 0.57 \mathrm{mmHg}$, respectively). Cystometric analysis of statically incubated bladders produced P-V curves with an overall curve trend comparable to the one from the dynamically perfused group (data not shown). However, statistically significant differences (Student's $t$-test, $p=0.036$ ) emerged by comparing the P-V curve slope in the $V_{1}-V_{2}$ region of the dynamic vs the static group. The different mechanical response to continuous organ filling may reflect the different degree of collagen and elastic fiber preservation observed in the two groups through Mallory's trichrome and Orcein staining (Fig. 5). 


\section{Discussion}

\section{The whole full-thickness bladder dynamic decellularization protocol}

It is widely recognized that for the BAM to retain physiologic functionality it is strictly necessary to preserve the physical and mechanical properties of the bladder ECM during the decellularization Gilbert et al. (2006), Crapo et al. (2011), Badylak et al. (2011). Accordingly, in this study we developed a decellularization protocol focusing on the retention of key structural and functional ECM components. Firstly, we employed decellularization of the whole intact bladder, avoiding any surgical maneuver such as mechanical delamination of the tissue before the exposure to detergents, in the belief that full-thickness tissue may yield improved functionality in the perspective of in vivo BAM grafting. Furthermore, we chose the decellularization agents with the criterion of minimally affecting the ECM protein-protein bonds, i.e.: hypotonic solution, causing cell membrane lysis, and a mild non-ionic detergent solution, to disrupt cell-ECM interactions (DNAprotein, lipid-lipid and lipid-protein interactions). Similar approaches have been previously reported to provide efficient decellularization of the liver, kidney, pancreas and intestine of various animal sizes and species Baptista et al. (2009), Shupe et al. (2010), Baptista et al. (2011). Lastly, an automated dynamic system was developed exposing the bladder to cyclic distension to limit the time of chemical detergents tissue exposure, thanks to enhanced cell removal efficiency. The whole-organ dynamic approach we employed represents the innovative step of our protocol with respect to the bladder decellularization state-of-the-art Bolland et al. (2007), Rosario et al. (2008), Yang et al. (2010). An optimized dynamic decellularization protocol was identified, by selectively varying the working parameters expected to primarily affect cell removal and the retention of bladder ECM ultrastructure and biomechanical properties. The optimized protocol consisted in an overall $17-\mathrm{h}$ dynamic treatment, with a $5-\mathrm{ml} / \mathrm{min}$ infusion flow rate and a $20-\mathrm{ml}$ maximum distention volume. Indeed, according to our results, the dynamic protocol resulted in a significant elimination of DNA and RNA from the tissue, equal to $98.5 \%$ and $95 \%$, respectively, with residual DNA content lower than $50 \mathrm{ng} / \mathrm{mg}$ dry tissue weight. Thus, even though immunogenicity of the achieved BAM was not assessed in the present work, according to literature, the obtained acellular matrix appeared unlikely to induce poor cytocompatibility or to elicit adverse tissue remodeling, host inflammatory response or severe immune reaction Ozeki et al. (2006), Bolland et al. (2007), Ott et al. (2008), Rosario et al. (2008), Baptista et al. (2011). As a result, the decellularization protocol established in this work represents a promising procedure for the extraction of a BAM tissue patch to be engrafted in pathological bladders. 
Conversely, cell nuclei were not adequately removed after a $17-\mathrm{h}$ static incubation. We therefore improved the efficacy of the decellularization in terms of process duration with respect to previous works, which reported bladder full static decellularization with procedures lasting 48-72h Yang et al. (2010), Rosario et al. (2008), Bolland et al. (2007). Indeed, from our study, it appears that, in static incubation, the purely diffusionbased delivery of the decellularising agents is insufficient to promote complete cell removal from the inner layers of the ECM. In this respect our findings are in accordance with evidences reported in Baptista et al., who demonstrated that the tissue matrix constitutes a barrier to diffusion at the outer surface, preventing efficient access of the detergents to the deeper parenchyma Baptista et al. (2009). In our dynamic distention system, the delivery of the decellularising agents was supplemented by convection mechanisms; this, together with the effect of ECM fluid turnover induced locally by cyclic wall distention, was effective in overcoming the limitations related to long-lasting static treatments.

\section{BAM 3D ultrastructure}

Histological staining revealed a partial ECM ultrastructure modification following the decellularization. Nevertheless, it is recognized that the ECM fibers must be adequately disrupted during the decellularization process to allow for exposure of all cells to the decellularising agents and to provide a path for the cellular debris to be removed from the tissue Gilbert et al. (2006). This phenomenon was indeed observed in previous studies by other groups and associated to the (indispensable) removal of the cells lying in the gaps among the extracellular fibrous structures L'Heureux N (1993), Ozeki et al. (2006), Badylak et al. (2011), Heine et al. (2011). Interestingly though, we observed a good degree of preservation of the collagen matrix structure and of the elastic fibers distribution in the dynamically treated BAM with respect to the static samples, suggesting that the cyclic filling/voiding approach, beyond being beneficial in terms of cell removal, was conservative with respect to the ECM protein architecture. It is worth to notice that during dynamic distention the organ experiences a cyclic loading state more similar to the bladder cyclic distention occurring in vivo, while static incubated samples were subjected to a continuous and long-lasting distention dramatically affecting the ECM architecture.

Biomechanical and distention properties of native and acellular matrix 
A twofold approach was employed to gain insight into the effects induced by the decellularization upon the biomechanical behavior of the acellular tissue. UTL tests were used for plain tissue characterization, whereas ex-vivo filling cystometry was chosen to describe whole-organ mechanics.

BAM UTL tests indicated that our mild chemical aggression minimally affected the acellular ECM biomechanical properties. Indeed, static incubation up to $17 \mathrm{~h}$ led to a matrix owning biomechanical behaviour with great similarities to the native tissue, avoiding the modification of the mechanical characteristics that have been associated to the use of ionic detergents Bolland et al. (2007), Gratzer et al. (2006). Comparable results were obtained in the dynamic group, proving that the cyclic mechanical distention was not detrimental in preserving native-like biomechanical properties of the acellular ECM.

We observed the lack of any significant directional anisotropy in the biomechanical properties of the lower body region of the native rabbit bladder wall, as well as after the decellularization. To date, to the authors' knowledge, no published data evaluating potential anisotropy in the rabbit bladder are available; thus, it appears that a critical analysis of our data with respect to the literature in this field is impracticable. Our findings are in agreement with the study by Gloeckner et al. who reported isotropic mechanical behaviour of rat bladders Gloeckner et al. (2002) but seem to be in contrast with other studies in which mechanical anisotropy was found in native bladders of porcine origin Bolland et al. (2007), Korossis et al. (2009). On the other hand, Freytes et al. described that the same ECM (i.e., the same tissue or organ source) harvested from different species can exhibit different mechanical properties, suggesting that isotropic/anisotropic response of the bladder ECM might be strictly related to the specific investigated animal species Freytes et al. (2005). Nevertheless, despite the differences found in the isotropic response of the rabbit bladder, the order of magnitude of each of the six parameters we estimated from the stress-strain curves of the native tissues was comparable with the data reported by Korossis et al. for the porcine bladder tissue Korossis et al. (2009).

Concerning ex-vivo filling cystometry, we borrowed this method from clinical cystometry, a procedure routinely used to evaluate bladder urinary storage function and used as a component for the diagnosis of various bladder disorders. In this work, cystometric analysis was aimed at establishing the passive distention properties of the ECM in the acellular organs in response to in vivo-like intravescical filling. Cystometric analysis revealed that the P-V relationship of the acellular bladders differed sensibly from the native curve. In particular, the major change was a considerable increase of the zero-pressure volume, i.e., the largest intravescical volume at zero intravescical pressure $\left(\mathrm{V}_{1}\right.$ in Fig. 8), associated with an almost complete loss of structural tone at low infusion volumes. In consideration of histological observations, it seems quite 
reasonable to assume that this change was a direct result of the removal of the cells from the matrix. In particular, the complete depletion of muscular component implies loss of its structural role in the stiffening of the native matrix during filling. On the other hand, cell removal is liable to create gaps in the ECM and this, combined with a partial loss of the fibrillar texture, may give the matrix a way to reorganize and reshape in the form a looser structure. At a first glance, cystometric results may seem to clash with UTL data, which demonstrated, basically, unaltered biomechanical properties of the BAM. However, it is worth to notice that in UTL testing tissue strips were pre-tensioned before loading the samples, thus, they were loaded immediately as soon as they were elongated by the testing machine, whereas the tissue in the acellular bladders was not stretched instantly with early volume infusions, rather a sort of pre-inflation was required to effectively stretch the wall fibers to withstand a pressure increment. Over $V_{1}$ (Fig. 8) instead, acellular bladders were effectively stretched and a pressure increment comparable with the native condition was observed, which is consistent with the observations drawn from the UTL tests. Then, in the last region of the P-V curve $\left(\mathrm{V}>\mathrm{V}_{2}\right.$ in Fig. 8), a slope decrease was observed with the pressure exhibiting quasi-plateau phase. This behavior may be explained considering the removal of urothelial cells, representing the natural barrier preventing the intravescical fluids from infiltrating the subepithelial layer. In bladder decellularization, however, the removal of the urothelial cells was an essential requisite to allow the detergents to penetrate within the inner tissue layers to promote complete cell removal. Moreover, the massive cell removal from the inner tissue layers lead to increased interfibrillar space with such effect contributing to increase matrix porosity. Consequently acellular bladders were characterized by higher fluid permeability, particularly in the overstretched state. Accordingly, the low intravescical pressure increment against continuous intravescical filling above $V_{2}$ was representative of filtration of the infused fluid across the ECM pores Farhat et al. (2003), Cartwright et al. (2006). In perspective, BAM recellularization, in vitro through urothelial and/or muscular cell seeding prior to scaffold implantation, or in vivo thanks to cell infiltration from the host tissue in the implanted scaffold, could restore a proper bladder permeability barrier preventing urine leakage.

\section{Conclusions}

In this study, a protocol combining a physical and a chemical approach for the dynamic decellularization of whole full-thickness rabbit bladder was established, representing a first step toward the attainment of a biological-derived scaffold for bladder regeneration. Several preservation techniques were adopted to preserve the ECM 3D histo-architecture and structural components regulating the tissue mechanical behavior, including limitation of the tissue exposure time to the action of the chemical detergents, the use of 
detergents minimally affecting the ECM of the tissue and limitation of the bladder distention volume to not overstretch the bladder wall. Our protocol constitutes a promising alternative to counterbalance the tissue deterioration attributable to the use of ionic and/or enzymatic decellularization agents and the long-lasting standard static incubation approaches. Moreover, this study highlights the utility of dynamic decellularization to generate whole organ biological scaffolds, with significant potential for organ bioengineering. Nevertheless, limitations of the present study should be addressed in the near future, with particular attention to i) better elucidate the effects of the chemical detergents during the acellular tissue preparation (immunohistochemistry of the BAM elastic fibers, analysis of glycosamminoglycan content, analysis of BAM porosity, among others), and ii) analysis of the immunogenicity of the BAM by in vitro recellularization experiments and in vivo implant of the BAM in animal models. These studies would be beneficial toward the realization of a functional tissue patch ideally suited for use as an implant for bladder augmentation.

\section{Acknowledgments}

This work is supported by the Italian Ministry of Education, University and Research grant PRIN 2008YZNAHR.

\section{References}

ANDERSSON, K. E. \& ARNER, A. 2004. Urinary bladder contraction and relaxation: Physiology and pathophysiology. Physiological Reviews, 84, 935-986.

ATALA, A. 2007. Engineering tissues, organs and cells. J Tissue Eng Regen Med, 1, 83-96.

BADYLAK, S. F., FREYTES, D. O. \& GILBERT, T. W. 2009. Extracellular matrix as a biological scaffold material: Structure and function. Acta Biomater, 5, 1-13.

BADYLAK, S. F., TAYLOR, D. \& UYGUN, K. 2011. Whole-Organ Tissue Engineering: Decellularization and Recellularization of Three-Dimensional Matrix Scaffolds. Annual Review of Biomedical Engineering, Vol 13, 13, 27-53.

BAPTISTA, P. M., ORLANDO, G., MIRMALEK-SANI, S. H., SIDDIQUI, M., ATALA, A. \& SOKER, S. 2009. Whole Organ Decellularization - A Tool for Bioscaffold Fabrication and Organ Bioengineering. Embc: 2009 Annual International Conference of the Ieee Engineering in Medicine and Biology Society, Vols 1-20, 6526-6529.

BAPTISTA, P. M., SIDDIQUI, M. M., LOZIER, G., RODRIGUEZ, S. R., ATALA, A. \& SOKER, S. 2011. The Use of Whole Organ Decellularization for the Generation of a Vascularized Liver Organoid. Hepatology, 53, 604-617.

BOLLAND, F., KOROSSIS, S., WILSHAW, S. P., INGHAM, E., FISHER, J., KEARNEY, J. N. \& SOUTHGATE, J. 2007. Development and characterisation of a full-thickness acellular porcine bladder matrix for tissue engineering. Biomaterials, 28, 1061-1070.

BROWN, A. L., FARHAT, W., MERGUERIAN, P. A., WILSON, G. J., KHOURY, A. E. \& WOODHOUSE, K. A. 2002. 22 week assessment of bladder acellular matrix as a bladder augmentation material in a porcine model. Biomaterials, 23, 2179-90.

BROWN, B., LINDBERG, K., REING, J., STOLZ, D. B. \& BADYLAK, S. F. 2006. The basement membrane component of biologic scaffolds derived from extracellular matrix. Tissue Eng, 12, 519-26. 
BROWN, B. N., BARNES, C. A., KASICK, R. T., MICHEL, R., GILBERT, T. W., BEER-STOLZ, D., CASTNER, D. G., RATNER, B. D. \& BADYLAK, S. F. 2010. Surface characterization of extracellular matrix scaffolds. Biomaterials, 31, 428-37.

CARTWRIGHT, L. M., SHOU, Z. P., YEGER, H. \& FARHAT, W. A. 2006. Porcine bladder acellular matrix porosity: Impact of hyaluronic acid and lyophilization. Journal of Biomedical Materials Research Part A, 77A, 180-184.

CRAPO, P. M., GILBERT, T. W. \& BADYLAK, S. F. 2011. An overview of tissue and whole organ decellularization processes. Biomaterials, 32, 3233-3243.

DAHMS, S. E., PIECHOTA, H. J., DAHIYA, R., LUE, T. F. \& TANAGHO, E. A. 1998. Composition and biomechanical properties of the bladder acellular matrix graft: comparative analysis in rat, pig and human. British Journal of Urology, 82, 411-419.

DAVIS, N. F., MCGUIRE, B. B., CALLANAN, A., FLOOD, H. D. \& MCGLOUGHLIN, T. M. 2010. Xenogenic Extracellular Matrices as Potential Biomaterials for Interposition Grafting in Urological Surgery. Journal of Urology, 184, 2246-2253.

FARHAT, W., CHEN, J., ERDEJAN, P., SHEMTOV, O., COURTMAN, D., KHOURY, A. \& YEGER, H. 2003. Porosity of porcine bladder acellular matrix: Impact of ACM thickness. Journal of Biomedical Materials Research Part A, 67A, 970-974.

FREYTES, D. O., RUNDELL, A. E., VANDE GEEST, J., VORP, D. A., WEBSTER, T. J. \& BADYLAK, S. F. 2005. Analytically derived material properties of multilaminated extracellular matrix devices using the ball-burst test. Biomaterials, 26, 5518-5531.

GILBERT, T. W., SELLARO, T. L. \& BADYLAK, S. F. 2006. Decellularization of tissues and organs. Biomaterials, 27, 3675-83.

GLOECKNER, D. C., SACKS, M. S., FRASER, M. O., SOMOGYI, G. T., DE GROAT, W. C. \& CHANCELLOR, M. B. 2002. Passive biaxial mechanical properties of the rat bladder wall after spinal cord injury. Journal of Urology, 167, 2247-2252.

GRATZER, P. F., HARRISON, R. D. \& WOODS, T. 2006. Matrix alteration and not residual sodium dodecyl sulfate cytotoxicity affects the cellular repopulation of a decellularized matrix. Tissue Eng, 12, 2975-2983.

GRAUSS, R. W., HAZEKAMP, M. G., OPPENHUIZEN, F., VAN MUNSTEREN, C. J., GITTENBERGER-DE GROOT, A. C. \& DERUITER, M. C. 2005. Histological evaluation of decellularised porcine aortic valves: matrix changes due to different decellularisation methods. European Journal of CardioThoracic Surgery, 27, 566-571.

HEINE, J., SCHMIEDL, A., CEBOTARI, S., KARCK, M., MERTSCHING, H., HAVERICH, A. \& KALLENBACH, K. 2011. Tissue Engineering Human Small-Caliber Autologous Vessels Using a Xenogenous Decellularized Connective Tissue Matrix Approach: Preclinical Comparative Biomechanical Studies. Artificial Organs, 35, 930-940.

KIM, B. S., ATALA, A. \& YOO, J. J. 2008. A collagen matrix derived from bladder can be used to engineer smooth muscle tissue. World J Urol, 26, 307-14.

KOROSSIS, S., BOLLAND, F., SOUTHGATE, J., INGHAM, E. \& FISHER, J. 2009. Regional biomechanical and histological characterisation of the passive porcine urinary bladder: Implications for augmentation and tissue engineering strategies. Biomaterials, 30, 266-275.

L'HEUREUX N, G. L., LABBE R, AUGER FA 1993. In vitro construction of a human blood vessel from cultured vascular cells: a morphologic study. J Vasc Surg, 17, 499-509.

LIAO, J., JOYCE, E. M. \& SACKS, M. S. 2008. Effects of decellularization on the mechanical and structural properties of the porcine aortic valve leaflet. Biomaterials, 29, 1065-1074.

LOAI, Y., YEGER, H., COZ, C., ANTOON, R., ISLAM, S. S., MOORE, K. \& FARHAT, W. A. 2010. Bladder tissue engineering: Tissue regeneration and neovascularization of HA-VEGF-incorporated bladder acellular constructs in mouse and porcine animal models. Journal of Biomedical Materials Research Part A, 94A, 1205-1215.

OBARA, T., MATSUURA, S., NARITA, S., SATOH, S., TSUCHIYA, N. \& HABUCHI, T. 2006. Bladder acellular matrix grafting regenerates urinary bladder in the spinal cord injury rat. Urology, 68, 892-897.

OTT, H. C., MATTHIESEN, T. S., GOH, S. K., BLACK, L. D., KREN, S. M., NETOFF, T. I. \& TAYLOR, D. A. 2008. Perfusion-decellularized matrix: using nature's platform to engineer a bioartificial heart. Nature Medicine, 14, 213-221. 
OZEKI, M., NARITA, Y., KAGAMI, H., OHMIYA, N., ITOH, A., HIROOKA, Y., NIWA, Y., UEDA, M. \& GOTO, H. 2006. Evaluation of decellularized esophagus as a scaffold for cultured esophageal epithelial cells. Journal of Biomedical Materials Research Part A, 79A, 771-778.

PETERSEN, T. H., CALLE, E. A., ZHAO, L. P., LEE, E. J., GUI, L. Q., RAREDON, M. B., GAVRILOV, K., YI, T., ZHUANG, Z. W., BREUER, C., HERZOG, E. \& NIKLASON, L. E. 2010. Tissue-Engineered Lungs for in Vivo Implantation. Science, 329, 538-541.

REDDY, P. P., BARRIERAS, D. J., WILSON, G., BAGLI, D. J., MClORIE, G. A., KHOURY, A. E. \& MERGUERIAN, P. A. 2000. Regeneration of functional bladder substitutes using large segment acellular matrix allografts in a porcine model. J Urol, 164, 936-41.

RIEDER, E., KASIMIR, M. T., SILBERHUMER, G., SEEBACHER, G., WOLNER, E., SIMON, P. \& WEIGEL, G. 2004. Decellularization protocols of porcine heart valves differ importantly in efficiency of cell removal and susceptibility of the matrix to recellularization with human vascular cells. Journal of Thoracic and Cardiovascular Surgery, 127, 399-405.

RIVA, F., RAHMAN, M. M., TURIN, L., CECILIANI, F., RUSSO, S., TRIBBIOLI, G. \& LECCHI, C. 2010. TIR8 receptor expression in bovine tissues. Veterinary Immunology and Immunopathology, 136, 6570.

ROSARIO, D. J., REILly, G. C., SAlAH, E. A., GLOVER, M., BULLOCK, A. J. \& MACNEIL, S. 2008. Decellularization and sterilization of porcine urinary bladder matrix for tissue engineering in the lower urinary tract. Regenerative Medicine, 3, 145-156.

SHUPE, T., WILliaMS, M., BROWN, A., WILLENBERG, B. \& PETERSEN, B. E. 2010. Method for the decellularization of intact rat liver. Organogenesis, 6, 134-136.

SONG, J. J. \& OTT, H. C. 2011. Organ engineering based on decellularized matrix scaffolds. Trends in Molecular Medicine, 17, 424-432.

TURIN, L., RIVA, F., GALBIATI, G. \& CAINELLI, T. 2000. Fast, simple and highly sensitive doublerounded polymerase chain reaction assay to detect medically relevant fungi in dermatological specimens. European Journal of Clinical Investigation, 30, 511-518.

URAKAMI, S., SHIINA, H., ENOKIDA, H., KAWAMOTO, K., KIKUNO, N., FANDEL, T., VEJDANI, K., NUNES, L., IGAWA, M., TANAGHO, E. A. \& DAHIYA, R. 2007. Functional improvement in spinal cord injury-induced neurogenic bladder by bladder augmentation using bladder acellular matrix graft in the rat. World J Urol, 25, 207-213.

YANG, B., ZHANG, Y. F., ZHOU, L. H., SUN, Z. Y., ZHENG, J. H., CHEN, Y. \& DAI, Y. T. 2010. Development of a Porcine Bladder Acellular Matrix with Well-Preserved Extracellular Bioactive Factors for Tissue Engineering. Tissue Engineering Part C-Methods, 16, 1201-1211.

YANG, M., CHEN, C. Z., WANG, X. N., ZHU, Y. B. \& GU, Y. J. 2009. Favorable Effects of the Detergent and Enzyme Extraction Method for Preparing Decellularized Bovine Pericardium Scaffold for Tissue Engineered Heart Valves. Journal of Biomedical Materials Research Part B-Applied Biomaterials, 91B, 354-361.

\section{Appendix: Design of the dynamic decellularization system}

A multi-channel hydraulic system enabling cyclic mechanical distention of whole bladders during decellularization was designed, allowing the simultaneous treatment of multiple (up to five) organs during the same experimental campaign. The dynamic decellularization process is completely automated and consists of two different phases, alternately repeated for pre-determinable time duration, replicating the natural cyclic filling/voiding dynamics of bladders. In the filling phase a peristaltic pump (323D, Watson-Marlow, USA) delivers the solution containing the decellularising agents. A multi-channel flow distributor (ramp of five 3way stopcocks, Polymed s.r.l, IT) splits the flow within five independent hydraulic lines, each connected to one bladder sample. The voiding phase is driven by a geodetic pressure difference between the bladder 


\section{Figure 1}

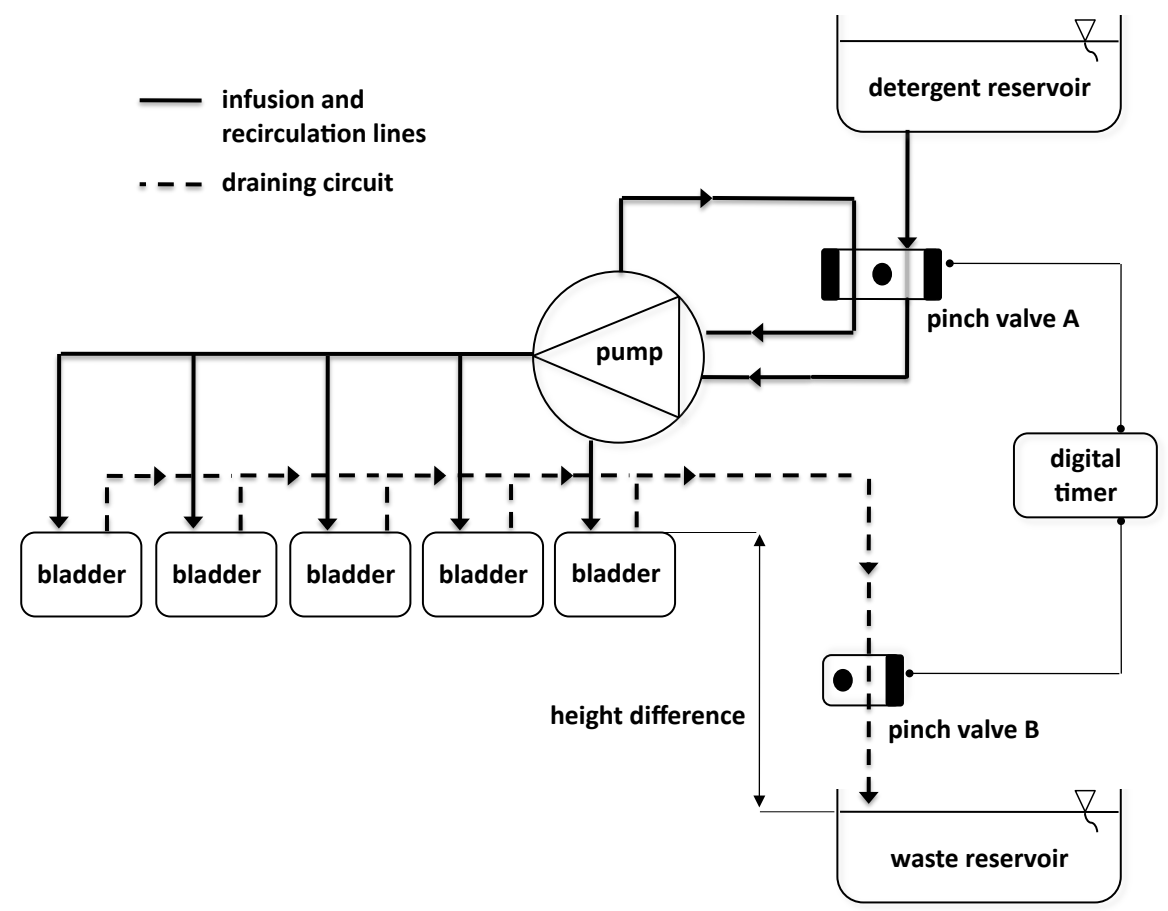

Figure 1: The schematics of the multi-channel dynamic decellularization system enabling automated cyclic distention of the bladder samples. Thick lines represent the hydraulic circuit, which includes an infusion and recirculation sub-sections (solid lines) driven by a peristaltic pump, and a draining sub-section (dashed lines), driven by a geodetic pressure difference between the bladder chambers and the waste reservoir. Thin lines depict the electrical connections between a programmable timer and two pinch valves, by which the cyclic opening/closure of the infusion/draining lines is controlled. 
Figure 2
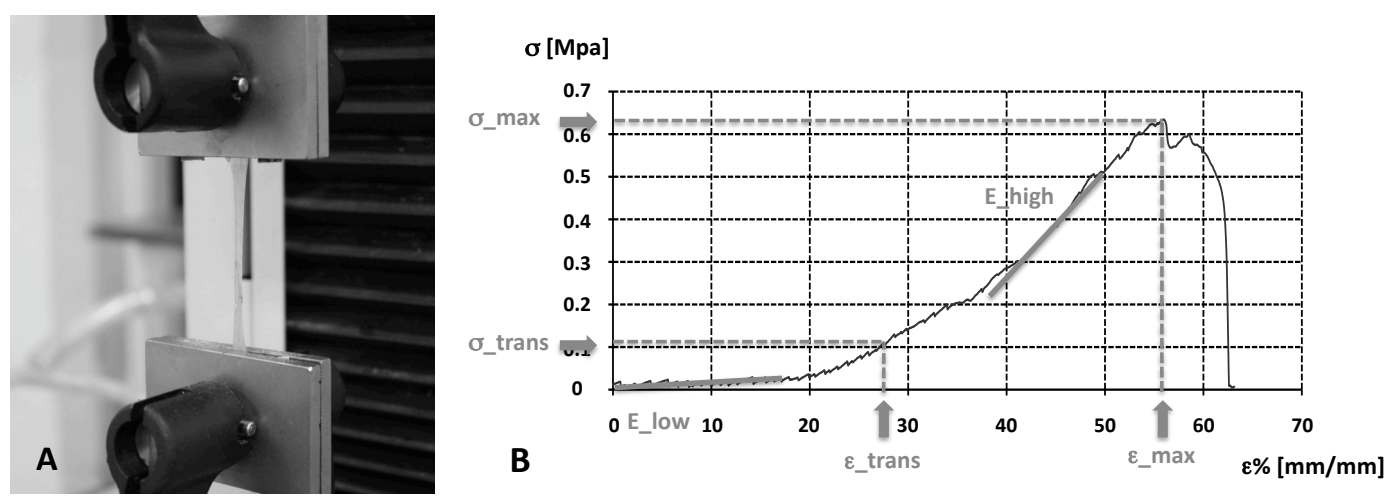

Figure 2: (A) Bladder wall tissue strip within the machine clamps during UTL test; (B) typical stress-strain curve showing the six parameters used for the tissue biomechanical characterization. Prior to loading to failure, the specimens were preconditioned by applying repeated load and relaxation cycles $(3 \mathrm{~mm} / \mathrm{min}$ strain rate) until the stress strain curves were superimposed: a strain equal to $30 \%$ and $10 \%$ with respect to the initial specimen length was imposed to the LB-AB and LB-T specimens, respectively. A pretension equal to $0.02 \mathrm{~N}$ was applied before loading the samples. UTL test to failure were then performed at a rate of 3 $\mathrm{mm} / \mathrm{min}$. 
Figure 3
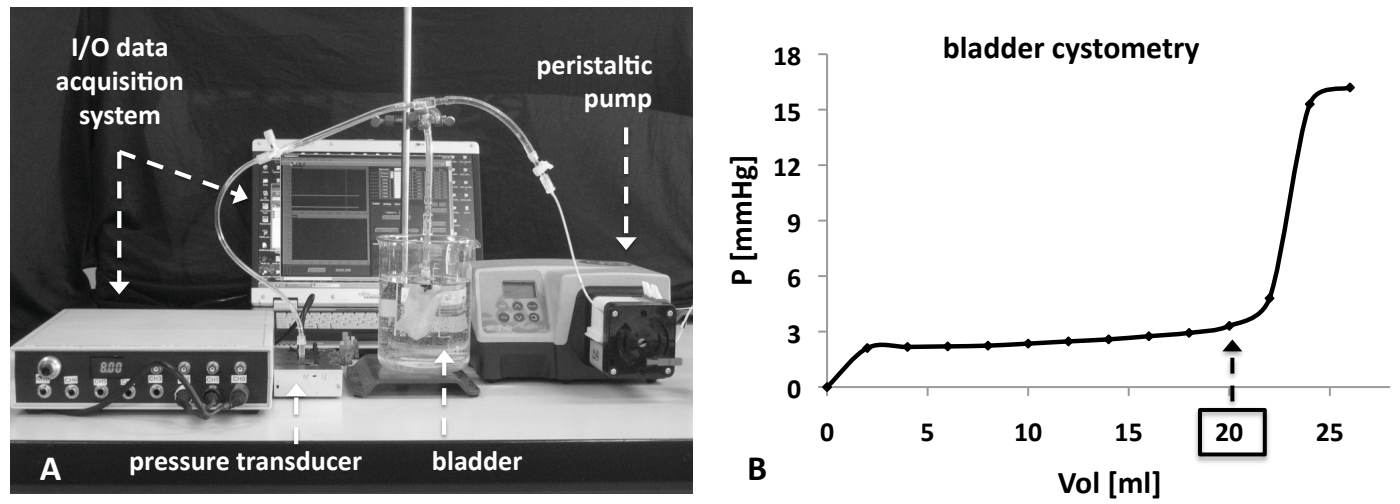

Figure 3: (A) The assembled experimental set-up for the ex-vivo filling cystometry measurement; (B) representative pressure-volume curve of the isolated native rabbit bladder: the arrow indicates the maximum distention volume (approximately $20 \mathrm{ml}$ ) not overstretching the bladder wall. 
Figure 4
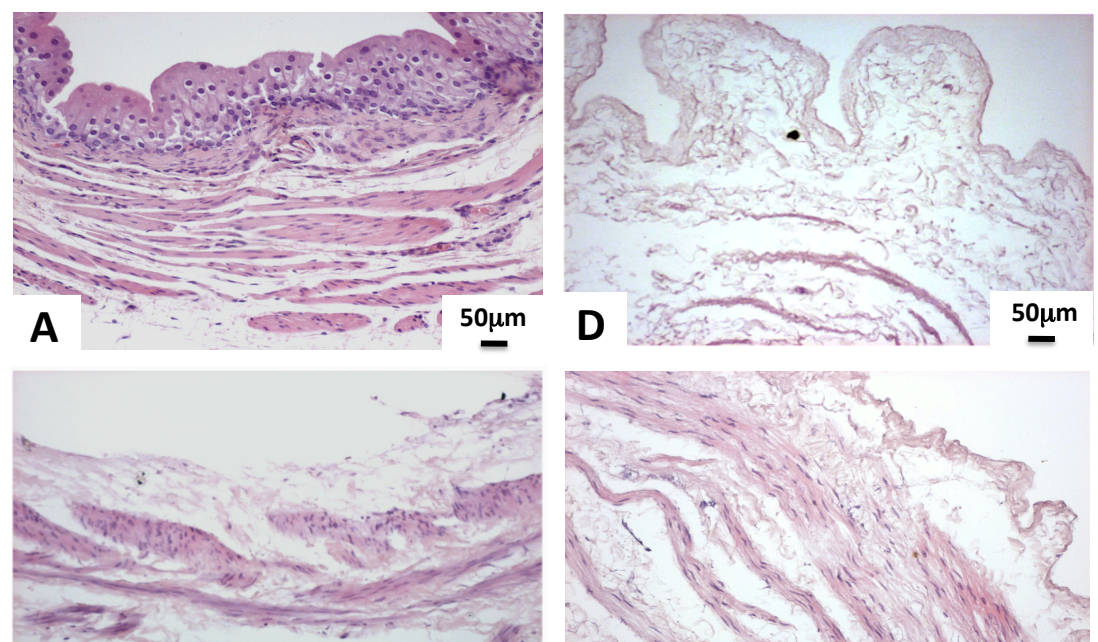

B

$50 \mu \mathrm{m}$
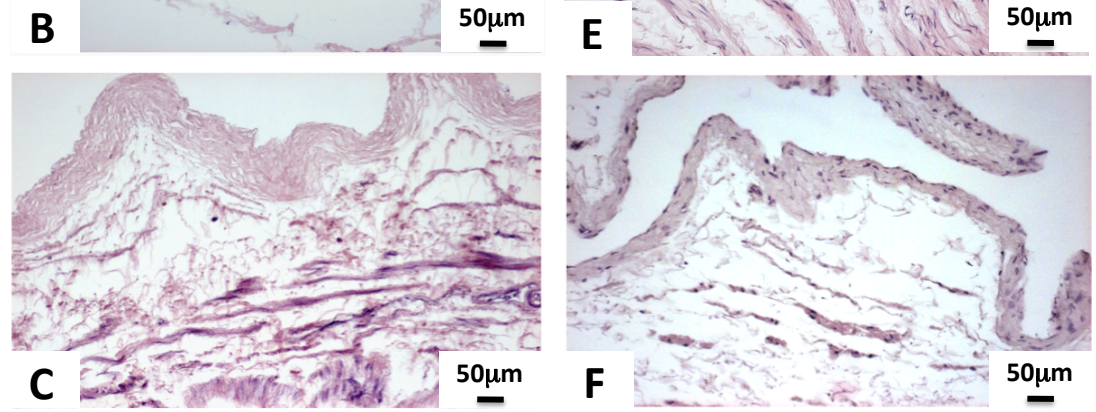

Figure 4: Haematoxylin and eosin staining of native and decellularised bladder tissue: (A) native tissue; (B) 4+4+1 h- $5 \mathrm{ml} / \mathrm{min}$; (C) 6+6+1 h - 5ml/min; (D) 8+8+1 h-5ml/min; (E) 8+8+1 h-3ml/min; (F) 8+8+1 h static incubation 
Figure 5

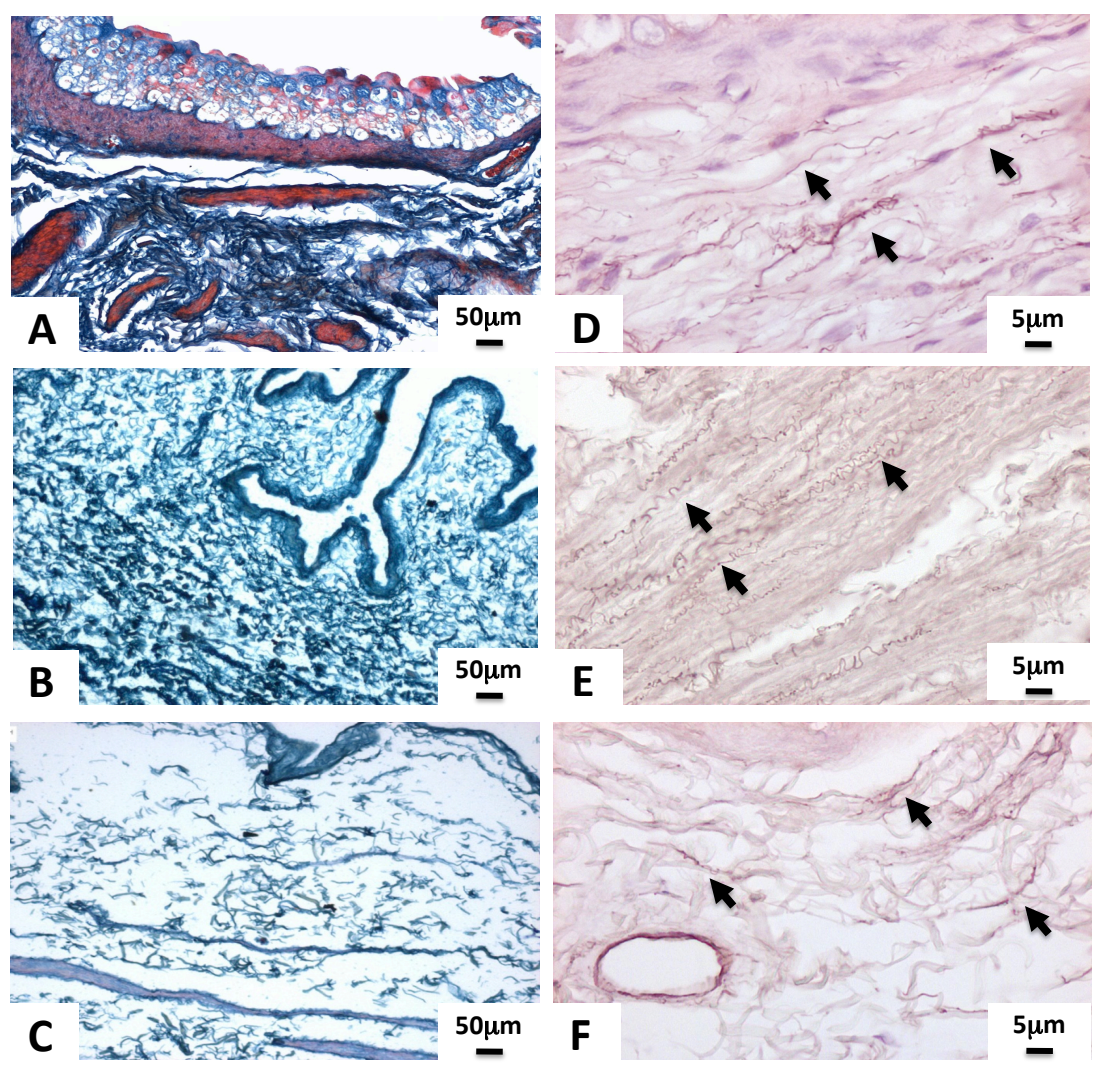

Figure 5: Mallory's trichrome (left) and Orcein staining (right) of native and decellularised bladder tissue; collagen and elastic fibers (black arrows indicate clearly visible elastic fibers) are shown for native (A, D), $8+8+1 \mathrm{~h}-5 \mathrm{ml} / \mathrm{min}$ samples $(\mathrm{B}, \mathrm{E})$ and the $8+8+1 \mathrm{~h}$ static incubation group $(\mathrm{C}, \mathrm{F})$. 
Figure 6

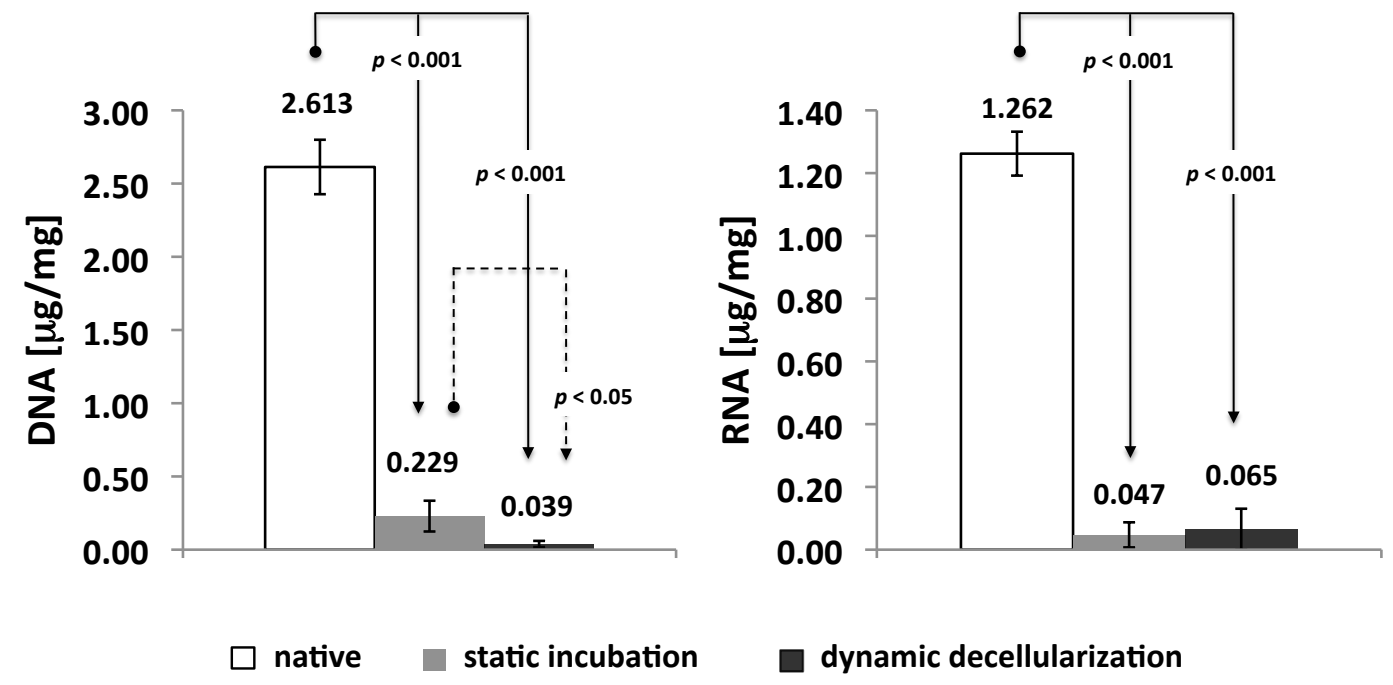

Figure 6: Analysis of residual DNA (left panel) and RNA (right panel) content in native, statically incubated and dynamically decellularized bladder tissue samples. Data are expressed as mean $\pm S D$; in figure, connectors indicate statistically significant $(p<0.05)$ difference between originator column and end arrow column; for all groups $n=5$. 
Figure 7
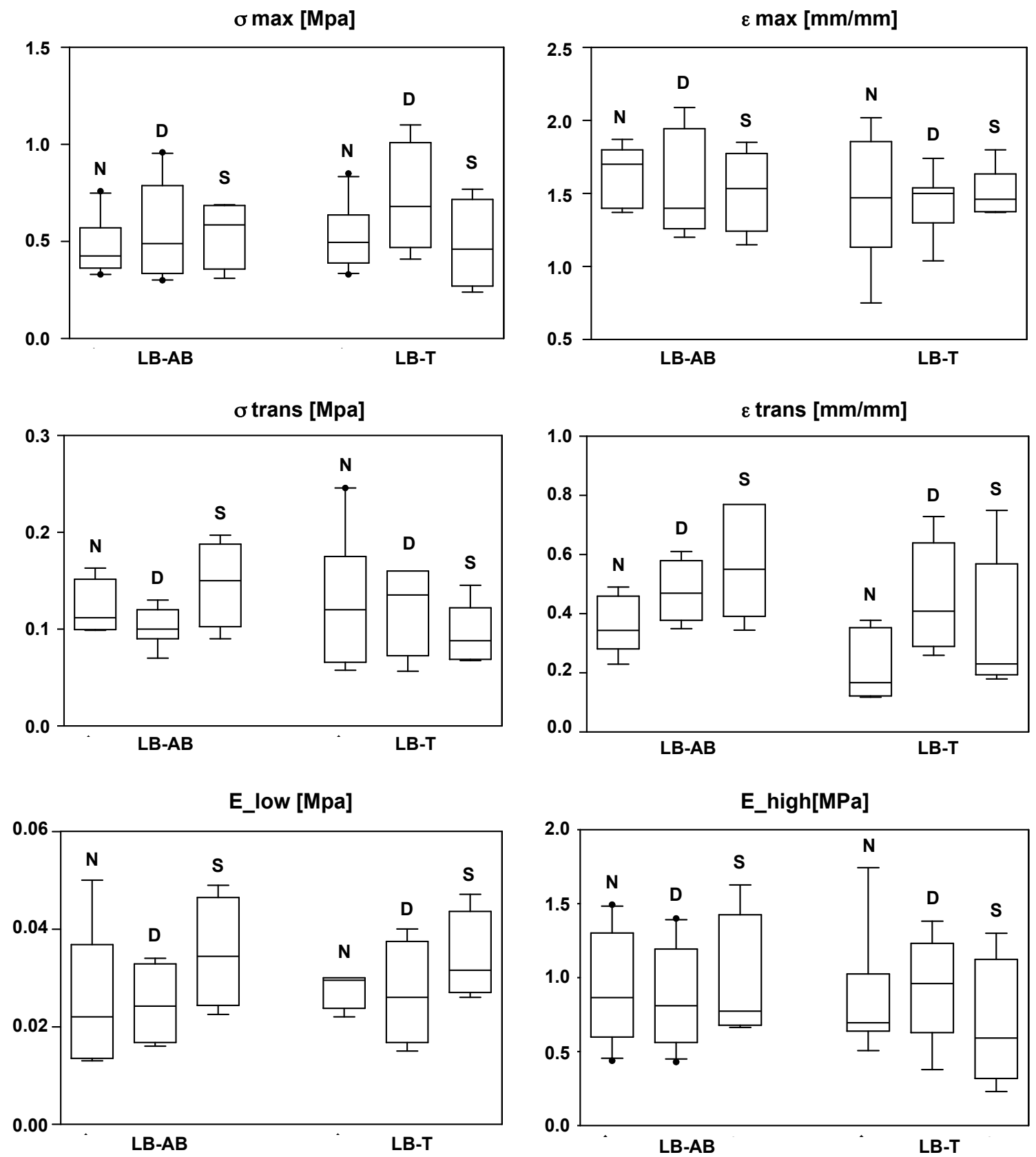

Figure 7: Biomechanical characterization of the native and decellularised tissue. Specimens were retrieved from the lower body (LB) region of the bladder wall along the apex-to-base (LB-AB) and transversal (LB-T) directions. Data are represented with inter-quartile range box plots and whiskers indicating $10^{\text {th }}$ and $90^{\text {th }}$ percentile. Solid lines in the box plot indicate the median value of each data set; for all groups, $n=10$. 
Figure 8
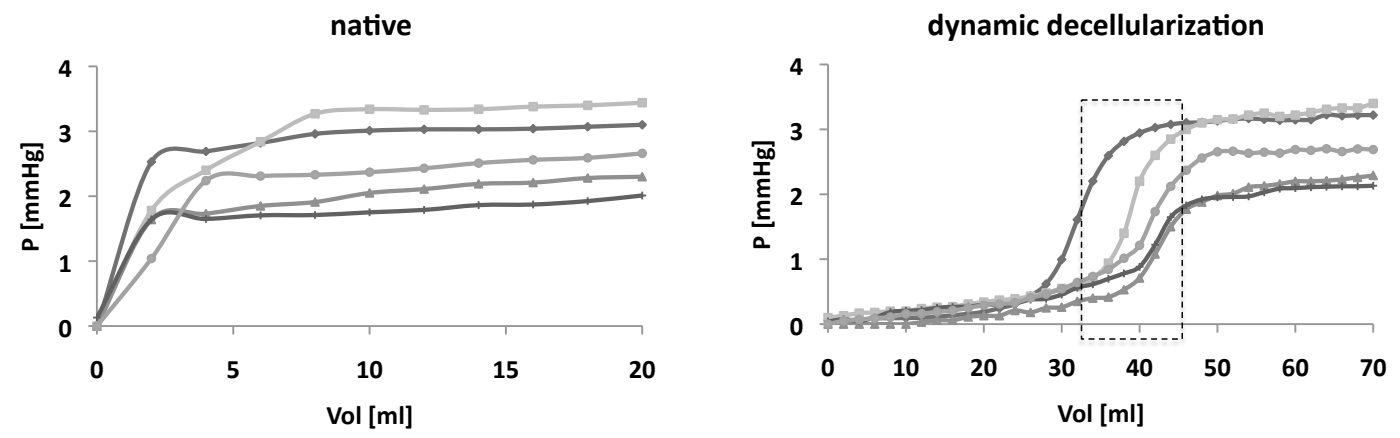

Figure 8: Cystometric P-V curves of native (A) and acellular bladders (B); in diagram $B$ the rectangle indicates the curve region within the early $\left(V_{1}\right)$ and the late $\left(V_{2}\right)$ curve slope transitions wherein acellular bladders are stretched withstanding an effective pressure increment; for all groups $n=5$. 